\title{
Urinary albumin excretion in diabetic pregnancy
}

\author{
D.R.McCance ${ }^{1}$, A. I.Traub ${ }^{2}$, J.M.G.Harley ${ }^{2}$, D.R.Hadden ${ }^{1}$ and L. Kennedy ${ }^{1}$ \\ ${ }^{1}$ Sir George E.Clark Metabolic Unit, Royal Victoria Hospital, and ${ }^{2}$ Royal Maternity Hospital, Belfast, Northern Ireland
}

\begin{abstract}
Summary. We have analysed the results of urinary albumin excretion in timed overnight urine samples once every two weeks during pregnancy and post-natally in 25 non-diabetic women and 14 women with Type 1 (insulin-dependent) diabetes who were Albustix negative and had urinary albumin excretion $<15 \mu \mathrm{g} \cdot \mathrm{min}^{-1}$ at conception. Urinary albumin excretion did not vary significantly in the first two trimesters in either group and at 28 weeks was $2.73 \mu \mathrm{g} \cdot \mathrm{min}^{-1}$ (0.32-251.68) (median and range) in the diabetic women and $2.53 \mu \mathrm{g} \cdot \mathrm{min}^{-1}(0.90-13.37)$ in control patients (not significant). During the third trimester urinary albumin excretion increased, and levels were significantly higher in diabetic patients from 36 weeks $(9.37 \quad(0.9-31.78) \quad$ vs 3.52 $\left.(0.19-33.74) \mu \mathrm{g} \cdot \mathrm{min}^{-1}, p<0.01\right)$ until delivery. In both
\end{abstract}

groups, urinary albumin excretion reached a peak within the week following delivery - diabetic $17.42 \mu \mathrm{g} \cdot \mathrm{min}^{-1}$ (2.03-46.64), control subjects $16.29 \mu \mathrm{g} \cdot \mathrm{min}^{-1}(1.53-35.56)$, but six weeks after delivery, levels were similar to those in early pregnancy. The effect of pregnancy on urinary albumin excretion in these diabetic women would appear to be an exaggeration of the normal pattern, with levels returning to normal post-delivery. It is not possible to know if this has significance for future renal function, but it would be important to investigate this phenomenon in patients who already have raised urinary albumin excretion at conception.

Key words: Urinary albumin excretion, diabetic pregnancy, microalbuminuria, pre-eclampsia.
The assessment of urinary protein is one of the most commonly used tests in clinical medicine, particularly in diabetes. Some 20 years after the initial use of radioimmunoassay for detecting small quantities of albumin in urine [1], there is considerable interest in the concept of 'microalbuminuria', (urinary albumin excretion which is greater than normal but lower than that detected by conventional "dipstick" testing) and its relevance to the pathogenesis and prevention of diabetic nephropathy $[2,3]$. Urinary albumin excretion can be $10-20$ fold higher than normal and yet clinically undetectable [4]. Several studies have shown that microalbuminuria is predictive of future diabetic nephropathy [5-8].

Glomerular hyperfiltration occurs physiologically in healthy pregnancy [9] and is also a feature of Type 1 (insulin-dependent) diabetes mellitus [10, 11]. A high gomerular filtration rate may lead to glomerular damage which is likely to increase with the duration of glomerular hyperfiltration [12]. Therefore, the excretion of albumin, which is a well established marker of glomerular damage [13], is particularly relevant in diabetic pregnancy where there is reason to believe that the kidneys may be damaged or vulnerable to damage.

We are aware of only three studies [14-16] in which the urinary albumin excretion has been measured throughout normal pregnancy and are unaware of any similar prospective study in diabetic pregnancy. We report here the serial quantitation of urinary albumin excretion in diabetic pregnancy and compare this to a normal healthy pregnant control group.

\section{Subjects and methods}

Sixteen women, with established Type 1 diabetes attending the regional referral antenatal diabetes clinic (either primarily or referred from a peripheral hospital) were studied serially during pregnancy to determine their urinary albumin excretion. They were aged 19-33 years; the duration of diabetes was 2-22 years; 10 patients were in their first pregnancy, and six had had a previous pregnancy. All were Albustix negative (Albustix, Ames Division, Miles Limited, Stoke Poges, Slough, UK) and had urinary albumin excretion $<15 \mu \mathrm{g} \cdot \min ^{-1}$ early in the pregnancy. One patient had chronic hypertension and received antihypertensive therapy for the duration 


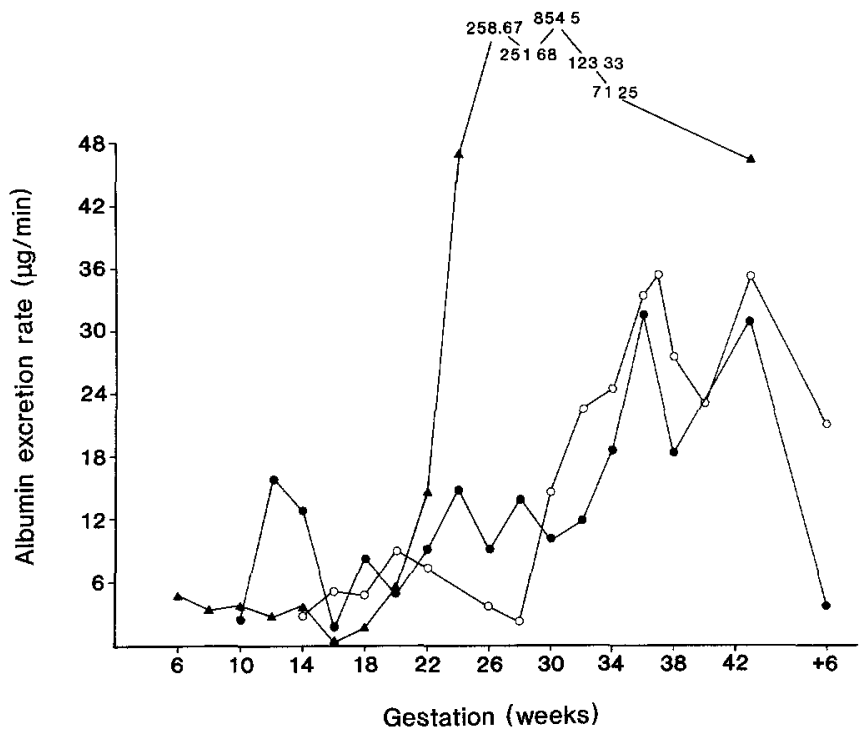

Fig. 1. Serial measurements of urinary albumin excretion in three patients in whom excessive variability was observed in the third trimester. ( $\longrightarrow$ ) diabetic patient with pre-eclampsia; $(\mathbf{O})$ diabetic patient with chronic hypertension; $\left(\mathrm{O}^{-} \mathrm{O}\right)$ grand multiparous control patient

of her pregnancy. Twenty-five healthy pregnant women aged $20-42$ years, with an uncomplicated past medical history and on no medication, served as control subjects. A non-diabetic non-pregnant reference range was established from 25 healthy female laboratory and medical staff aged $24.6 \pm 4.3$ y (mean $\pm S D)$.

Entry to the study was at the first ante-natal attendance or, thereafter, up to 18 weeks gestation. Entry was earlier in the diabetic group where $66 \%$ had entered by 12 weeks. Urine samples were obtained once every two weeks throughout pregnancy, within one week after delivery and at six weeks post-natally. The change in urinary albumin excretion during pregnancy is compared to the mean value at 18 weeks gestation, by which time the full complement of patients was available for comparison.

Timed overnight urine collections were used. Starting the evening before each visit to the clinic, the patient discarded the last sample before retiring to bed and retained all urine up to and including the first sample the next morning, and the time elapsed was noted. Urinary albumin excretion was measured using a double antibody ${ }^{125} \mathrm{I}$ radioimmunoassay technique (Diagnostic Products Ltd, Abingdon, Oxon, UK). The between batch and within batch coefficients of variation were 5 and $7 \%$ respectively. The detection limit of the assay was $0.9 \mu \mathrm{g} / \mathrm{ml}$. Any patient with suspected or proven urinary tract infection had albumin estimation deferred until culture was negative.

Weight, blood pressure and Albustix testing of urine were recorded and urine culture obtained every two weeks. Self-monitoring of capillary blood glucose was performed preprandially by the mothers and the results brought to the antenatal diabetes clinic review. Glycaemic control was also assessed by glycosylated haemoglobin, measured by agar gel electroendosmosis (Corning Ltd, Halstead, Essex, UK) with a reference range of $3.6 \cdots 7.2 \%$.

The study was approved by the Research Ethical Committee of Queen's University, Belfast, Northern Ireland, UK, and informed verbal consent obtained from both diabetic and control subjects.

\section{Statistical analysis}

There was considerable fluctuation in urinary albumin excretion in individual patients (Fig.1). Median values are given in addition to means, and the albumin/creatinine ratio has been calculated. Mann-
Whitney $U$ and Wilcoxon signed rank tests for paired differences were used for between and within group comparisons respectively as the urinary albumin measurements were asymmetrically distributed.

\section{Results}

In 25 non-diabetic non-pregnant women of childbearing age, the mean urinary albumin excretion was $1.97 \pm 1.28 \mu \mathrm{g} \cdot \mathrm{min}^{-1}($ mean $\pm \mathrm{SD})$ and albumin/creatinine ratio $0.41 \pm 0.23$. Median values were 1.52 $(0.44-4.69)$ and $0.3(0.1-0.9)$ respectively.

Two diabetic patients who were initially enrolled in the study were excluded from the analysis because of persisting refractory urinary infections which rendered their urinary albumin excretion results uninterpretable. Therefore, the results in the diabetic groups are those obtained in the remaining 14 patients.

Urinary albumin excretion in pregnancy for both the control group and the diabetic patients are shown in Figures 2 and 3 . The last observation before delivery is considered separately from the other third trimester observations.

For the non-diabetic pregnant women, mean urinary albumin excretion increased from $2.5 \mu \mathrm{g} \cdot \mathrm{min}^{-1}$ (range $0.14-5.69$ ) at 18 weeks to $4.03 \mu \mathrm{g} / \mathrm{min}$ $(0.21-14.68)$ at 30 weeks. The mean pre-delivery value was $3.93 \mu \mathrm{g} / \mathrm{min}(0.1-38.79)$. There was a rise within one week after delivery to $16.29 \mu \mathrm{g} \cdot \mathrm{min}^{-1}(5.3-35.56)$. Six weeks post-natally the level was $3.0 \mu \mathrm{g} \cdot \mathrm{min}^{-1}$ (0.85-21.23). In the diabetic group, from a similar value at 18 weeks, $2.92 \mu \mathrm{g} \cdot \min ^{-1}(0.63-8.41)$, urinary albumin excretion was increased at 32 weeks, $6.74 \mu \mathrm{g} \cdot \mathrm{min}^{-1}(0.75-123.33)$. This increase was also maintained pre-delivery, $12.97 \mu \mathrm{g} \cdot \mathrm{min}^{-1}(1.82-71.25)$ and within one week after delivery, $17.41 \mu \mathrm{g} \cdot \mathrm{min}^{-1}$ (2.03-46.64), but not six weeks post-natally, $3.7 \mu \mathrm{g} \cdot \min ^{-1}(1.12-12.79)$. Differences between the two groups were significant from 36 weeks until term $(p=0.008)$ but not immediately post-partum or at six weeks after delivery. Albustix/creatinine ratios showed almost identical trends (results not shown).

In the diabetic group mean $\mathrm{HbA}_{1}$ decreased from a mean booking value of $9.5 \%$ to $8.1 \%$ just before delivery $(p<0.05)$. In this group $\mathrm{HbA}_{1}$ correlated with urinary albumin excretion at 28 weeks $(r=0.6, p<0.05)$ but at no other time during pregnancy.

Mean birth weight in the diabetic group, $3526 \pm 927 \mathrm{~g}$, was slightly higher than in the control group, $3422 \pm 564 \mathrm{~g}$ (mean $\pm \mathrm{SD}$ ). There was no correlation between urinary albumin excretion and the birth weight or neonatal behaviour of the baby. The diabetic patients tended to have a slightly shorter mean gestational age, 36.5 weeks than the control group (38.2 weeks) but the Caesarean section rate was much higher in the former group ( $57 \%$ vs $16 \%$ ). Three diabetic patients developed polyhydramnios but in none of these was there any relation to glycaemic control or uri- 


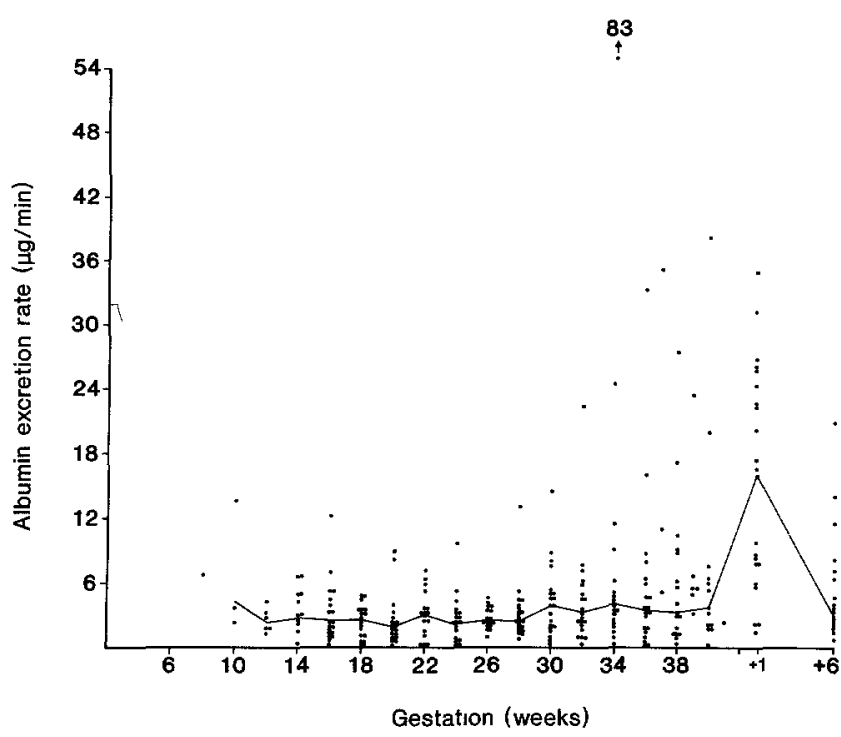

Fig. 2. Urinary albumin excretion in non-diabetic control women throughout pregnancy. (-) median

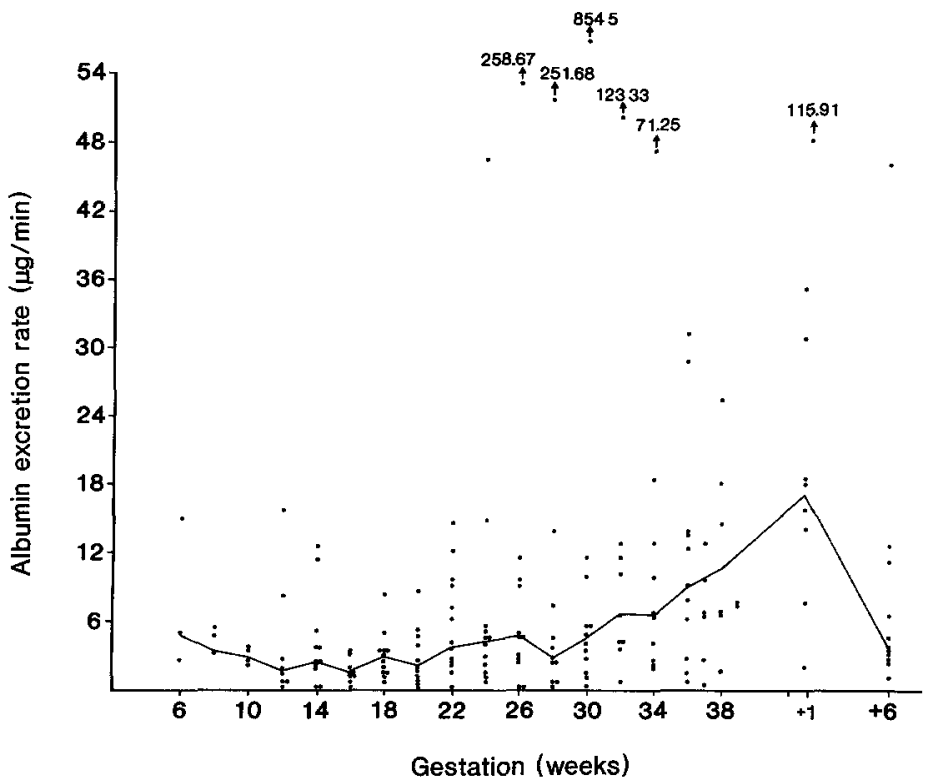

Fig.3. Urinary albumin excretion in pregnant diabetic women during pregnancy. (-) median

nary albumin excretion. Indeed, one of these patients, despite normal albumin excretion and impeccable glycaemic control was delivered of a baby weighing $5095 \mathrm{~g}$.

Three patients in each group developed preeclampsia - diastolic blood pressure $>90 \mathrm{~mm} \mathrm{Hg}$ plus mild to moderate oedema and/or Albustix positive proteinuria. In neither group, was there any evidence to suggest that pre-eclampsia was antedated by an increase in urinary albumin excretion. With the exception of one diabetic patient, the highest value for urinary albumin excretion in the patients who developed pre-eclampsia was observed in the post-natal period.

\section{Discussion}

Urinary albumin excretion varies widely in individuals in the resting state [17] and is markedly influenced by posture [18], exercise [19-21], blood pressure changes [22] and dietary protein intake [23]. The mode of collection [5, 7-9] is, therefore, relevant to this variability and the interpretation of results. A recent study concluded that overnight urine collections were more precise than day time collections for the determination of albumin excretion rates, with an acceptable variability between sampling $[17,24]$. Unlike Wright et al., who used a random urine collection [15], we were able to confirm an increase in urinary albumin excretion during pregnancy. Like LopezEspinoza et al. [14] and Gero et al. [16] (who used a $24 \mathrm{~h}$ urinary collection), we observed a progressive increase from 28 weeks gestation in normal pregnancy, peaking within one week of delivery, but not remaining significantly elevated at six weeks post-natally.

The effect of pregnancy on urinary albumin excretion in diabetic women without microalbuminuria at the time of conception would appear to be an exaggeration of the normal pattern, with levels returning to normal post-delivery. Why the maximum urinary albumin excretion occurs post-natally remains ill defined. It is well recognised that the early puerperium is a time of dramatic haemodynamic readjustment with a 20-30\% increase in cardiac output above pre-labour values owing to an increase in stroke volume, which remains raised for at least $48 \mathrm{~h}$ [25]. It would appear from the small number of patients we have studied that neither diabetic nor non-diabetic pre-eclampsia is antedated by any increase in urinary albumin excretion that might provide the clinician with a clue to impending complications. In view of the fact that microalbuminuria may temporarily increase, and pregnancy may aggravate retinopathy, nephropathy or uncontrolled hypertension in the diabetic woman [26], it would obviously be important to investigate this phenomenon in patients who already have raised urinary albumin excretion before conception.

\section{References}

1. Keen $\mathrm{H}$, Chlouverakis $\mathrm{C}$ (1964) Urinary albumin excretion and diabetes (letter). Lancet II: $1155-1156$

2. Viberti GC, Keen $H$ (1984) The patterns of proteinuria in diabetes mellitus. Diabetes 33: 686-692

3. Gatling W (1985) What is microalbuminuria? Practical Diabetes 2: $17-19$

4. Mogensen CE (1976) Renal function changes in diabetes. Diabetes 25: $872-879$

5. Viberti GC, Jarrett RJ, Mahmud U, Hill RD, Argyropoulos A, Keen H (1982) Microalbuminuria as a predictor of clinical nephropathy in insulin-dependent diabetes mellitus. Lancet I: $1430-1432$

6. Parving H-H, Oxenboll B, Svendson PAa, Sandahl Christiaensen J, Andersen AR (1982) Early detection of patients at risk of developing diabetic nephropathy. A longitudinal study of urinary albumin excretion. Acta Endocrinol 100: 500-555 
7. Mathiesen ER, Oxenboll B, Johansen K, Svendsen PAa, Deckert $\mathrm{T}$ (1984) Incipient nephropathy in Type 1 (insulin-dependent) diabetes. Diabetologia 26: 406-410

8. Mogensen CE, Christensen CK (1984) Predicting diabetic nephropathy in insulin-dependent patients. $\mathrm{N}$ Engl $\mathrm{J}$ Med 311: 89-93

9. Davidson JM, Hytten FE (1974) Glomerular filtration rate during and after pregnancy. Br J Obstet Gynaecol 81: 588-595

10. Mogensen CE (1971) Kidney function and glomerular permeability to macromolecules in early juvenile diabetes mellitus. Scand J Clin Lab Invest 28: 79 90

11. Hossetter TH (1985) Diabetic nephropathy. N Engl J Med 312: 642-644

12. Brenner BM, Meyer TW, Hostetter TH (1982) Dietary protein intake and the progressive nature of kidney disease: the role of a haemodynamically-mediated glomerular injury in the pathogenesis of progressive glomerular sclerosis in aging, renal ablation and intrinsic renal disease. N Engl J Med 307: 652-659

13. Hardwicke J, Squire JR (1955) The relationship between plasma albumin concentration and protein excretion in patients with proteinuria. Clin Sci 14: 509-530

14. Lopez-Espinoza I, Dhar H, Humphreys S, Redman WG (1986) Urinary albumin excretion in pregnancy. Br J Obstet Gynaecol 93 : 176-181

15. Wright A, Steele P, Bennett JR, Watts G, Polak K (1987) The urinary excretion of albumin in normal pregnancy. Br J Obstet Gynaecol 94: 408-412

16. Gero G, Davis FAM, Richardson MC, Dennis KJ, Rowe DJF (1987) Retinal-binding protein, albumin and total protein excretion patterns during normal pregnancy. J Obstet Gynaecol 8: 104-108

17. Chachati A, von Frenckell R, Foldart-Willems J, Godon JP, Lefebvre PJ (1987) Variability of albumin excretion in insulindependent diabetics. Diabetic Medicine 4: 441-445

18. Mogensen CE (1971) Urinary albumin excretion in early and longterm juvenile diabetes. Scand J Clin Lab Invest 28: 183-193
19. Viberti GC, Jarrett RJ, McCartney M, Keen $H$ (1978) Increased glomerular permeability to albumin induced by exercise in diabetic subjects. Diabetologia 14: 293-300

20. Vittinghus E, Mogensen CE (1982) Graded exercise and protein excretion in diabetic man and the effect of insulin treatment. Kid Int 21: 725-729

21. Mogensen CE, Vittinghus E, Solling K (1979) Abnormal albumin excretion after two provocative renal tests in diabetes: physical exercise and lysine injection. Kidney Int 16:385-393

22. Wiseman $M$, Viberti GC, Mackintosh D, Jarrett RD, Keen $H$ (1984) Glycaemia, arterial pressure and microalbuminuria in type 1 (insulin-dependent) diabetes mellitus. Diabetologia 26 : 401-405

23. Cohen D, Dodds R, Viberti GC (1987) Effect of protein restriction in insulin-dependent diabetes at risk of nephropathy. Br Med J 294: 795-798

24. Young M, Davis M, Richardson MC, Dennis KJ (1984) Urinary protein excretion in normal pregnancy. Proceedings of the 4th World Congress of the International Society for the Study of Hypertension in Pregnancy, p 192

25. Robson SC, Dunlop W, Hunter S (1987) Haemodynamic changs during the early puerperium. Br Med J 294: 1065

26. Hadden DR (1982) Endocrine and metabolic disorders. Clin Obstet Gynaecol 9: 29-57

Received: 28 September 1988

and in revised form: 9 February 1989

Dr. L. Kennedy

Sir George E. Clark Metabolic Unit

Royal Victoria Hospital

Belfast BT12 6BA

Northern Ireland 